\title{
Sensitization of the rat's acoustic startle response by repetition of a photic stimulus
}

\author{
JOHN M. RUSSO and JAMES R. ISON \\ University of Rochester, Rochester, New York 14627
}

\begin{abstract}
Acoustic startle responses were elicited in rats during trains of light flashes and during periods of darkness. In Experiment 1, startle vigor was potentiated within the first 30 sec of visual stimulation and remained above dark-control values for the 120-sec duration of each photic treatment. Motor activity increased quickly during the first train of flashes but then habituated and returned to the dark-control baseline. In Experiment 2, the time course of sensitization within the first $32 \mathrm{sec}$ of the photic treatment was found to be an increasing logarithmic function of the duration of visual stimulation. In these experiments reflex sensitization did not diminish with repeated stimulus exposure.
\end{abstract}

The present experiments examine changes in reflex sensitization in a paradigm in which sensitization is not confounded by concomitant changes in habituation. Repetition of an eliciting stimulus may simultaneously generate inhibitory habituation processes and excitatory sensitization processes, the ensuing behavioral outcome then reflecting their confounded net influence on reactivity (Groves \& Thompson, 1970). The bulk of present understanding of sensitization derives indirectly from empirically obtained habituation curves and derived hypothetical sensitization curves. It is assumed that the process of habituation should yield a steady decrement in response strength following stimulus repetition, but the behavioral decrement depends in large part on the temporal and intensive characteristics of the repeated stimulus, which may often yield local increases in response strength (Davis, 1970; Davis \& Wagner, 1968; Groves, Lee, \& Thompson, 1969). These perturbations are then ascribed to the occurrence of sensitization. As a result of this indirect approach, statements about the magnitude of sensitization, its decay over time, or its lability with repeated stimulation, have necessarily depended on the particular assumptions that jointly relate theoretical habituation and sensitization processes to the experimental manipulations. However appealing the derived arguments may be, this indirect approach should not substitute for an empirical examination of the growth of sensitization uninfluenced by the usually conjoint effects of habituation. The intent in the present research was to depict sensitization of a motor response (the rat's acoustic startle reaction) under conditions which are

This research was supported by a National Institute of Neurological and Communicative Diseases and Stroke research grant, NS 12443. Requests for reprints should be sent to Professor James R. Ison, Psychology Building, University of Rochester, Rochester, New York 14627. relatively free of the confounding influence of habituation.

We have argued (Russo, Reiter, \& Ison, 1975) that the procedure of habituating a response to a particular stimulus and then testing reactivity to stimuli presented in another modality is necessary for sensitization to be assessed independently of confounding habituation decrements. This strategy was employed here using a visual stimulus as the sensitizing agent. Ison, Hammond, and Krauter (1973) showed that repeated light-flash stimulation potentiated subsequent acoustic startle reactivity in rats without itself eliciting the startle response. This characteristic of the light flash permitted the present evaluation of changes in reflex excitability without interference from motor fatigue or habituation decrement in the referent $S-R$ pathway.

\section{EXPERIMENT 1}

In this first experiment, interest was focused on whether sensitization would decay spontaneously during protracted schedules of photic stimulation. Acoustic startle-eliciting stimuli were presented at a steady slow rate $(1 / 30 \mathrm{sec})$ throughout the experimental session, and trains of high-rate $(1 / \mathrm{sec})$ visual stimuli were periodically superimposed on this auditory schedule. Intervals were chosen that would provide opportunity for the decay of sensitization to be observed within an extended train of flashes (a relatively short-term decrement) and between trains (a longer-term decline).

Because Schwartzbaum, Kreinick, and Levine (1972) observed that photic stimulation increased activity levels in rats, we also measured motor activity in the interval between successive startle stimuli as an additional examination of the effects of photic stimulus iteration on habituation/sensitization. This permitted us to compare the effects of repetition on 
spontaneous behavior that is modulated by the repeated stimulus, i.e., activity, with the effects on a response associated with an independent stimulus, i.e., the acoustic startle reaction.

\section{Methods}

Subjects. The subjects were 25 naive male Sprague-Dawley rats obtained from the Charles River breeding colony. They were individually housed under ad-lib food and water conditions. Their weights at the time of running ranged from 260 to $350 \mathrm{~g}$.

Apparatus. The experimental chamber, measuring $8.5 \times 9.0 \times$ $19.5 \mathrm{~cm}$, was constructed of Plexiglas with side panels of brass bars. The chamber was rigidly mounted in an aluminum frame with an accelerometer (Statham Laboratories Model SA-2-300) attached to detect the rat's movements. This frame was held by compression springs within a second, free-standing aluminum frame. The output of the accelerometer was fed into one channel of a Beckman (Type R411) dynograph recorder and thence to a specially constructed sample and hold circuit with digital read-out display. The accelerometer output was also fed through an integrating circuit to a second channel of the dynograph, providing a measure of intertrial activity.

The acoustic startle stimulus was a 20-msec, 110-dB (SPL: re $\left.20 \mathrm{uN} / \mathrm{m}^{2}\right), 10-\mathrm{kHz}$ tone produced by a Hewlett-Packard oscillator (Model $200 \mathrm{AB}$ ) which fed through an electronic switch to a Stromberg Carlson 200-W power amplifier (Model APH 1200) and thence to a Calrad high-frequency tweeter. A millisecond timer controlled stimulus duration and spacing, and programming hardware controlled their number, order, and kind. The acoustic background was provided by a Grason-Stadler white-noise generator (Type 901-B), which fed into a separate 10-cm cone-type speaker at an intensity of $50 \mathrm{~dB}$ SPL.

Attached to the corners of the animal chamber were four dc light bulbs which provided the 10-msec, 4-fc light flashes. The experimental setup was housed in an Industrial Acoustics Co. sound-attenuating chamber located in a single-walled Industrial Acoustics Co. audiometric testing room. Intensities of all acoustic stimuli were measured from inside the animal chamber using a General Radio Co. precision sound-level meter (Type 1561) set at the "Flat" scale for the pure-tone stimulus and at the " $\mathrm{C}$ " scale for the white-noise background. A General Radio Co. impact noise analyzer (Type 1556-B) was used to measure startle-tone intensity. Visual stimuli were measured with a Spectra-Candela (Model X-100) light-level meter.

Procedure. The experimental session consisted of a pretest for reflex inhibition, followed by five blocks of four successive sensitization trials. Each trial consisted of 30 light flashes, delivered at a rate of $1 / \mathrm{sec}$, followed $1 \mathrm{sec}$ later by a single acoustic startle stimulus. Each trial in a block followed the preceding startle stimulus by $1 \mathrm{sec}$. Trains of 120 light flashes, delivered as four consecutive trials, were alternated with dark periods of $125 \mathrm{sec}$ duration, in which startle stimuli were delivered after $31,62,93$, and $124 \mathrm{sec}$. The type of starting condition, either photic stimulation or darkness, was balanced across subjects.

The rats were run individually in a single session that lasted approximately $40 \mathrm{~min}$. Each rat was placed into the experimental chamber and allowed $5 \mathrm{~min}$ of acclimatization to the apparatus and background noise level, after which it received two single startle tones, spaced $1 \mathrm{~min}$ apart, as a calibration procedure. One minute after the second tone, the experiment proper began with a pretest consisting of three types of trial: a control type (C), in which the acoustic startle stimulus was presented alone: a prepulse type (P60), in which the startle stimulus was preceded by a single light flash by $60 \mathrm{msec}$ : and a prepulse type (P1000), in which the startle stimulus was preceded by a single light flash by $1 \mathrm{sec}$. Each trial type was delivered five times in random order, with the limitation that no type was repeated until all types had been sampled an equal number of times. The intertrial interval in this phase of the experiment was $45 \mathrm{sec}( \pm 15 \mathrm{sec})$. The purpose of the pretest was to establish baseline sensitivity to a single light flash stimulus. The 60 -msec interval was chosen because Ison and Hammond (1971) showed that this interval produced reliable inhibition of the startle reaction, and inhibition may be taken as evidence that the rat has, in fact, processed the prestimulus (Russo et al., 1975). The longer interval was chosen because it was to be used later in assessing the effects of trains of flashes, and a measure of a single flash presented $1 \mathrm{sec}$ before eliciting the startle reaction was needed. Approximately $1 \mathrm{~min}$ after the last pretest trial, the sensitization treatment was begun.

Startle responses were scored as the voltage output of the accelerometer, integrated over a period of $100 \mathrm{msec}$ after the startle stimulus. Prior to the statistical analysis, each rat's score for each trial was converted to a proportion of the total startle amplitude exhibited by that rat for all conditions. This normalizing procedure is standard in our laboratory (see, e.g., Reiter \& Ison, 1977), as it removes from the analysis the effect of individual variation on overall reactivity. It could not be used, however, for activity scores, because many were near zero amplitude and their conversion to relative scores introduced unmanageable skew to this distribution. Therefore, activity was scored and analyzed as total millimeters of pen excursion $(1 \mathrm{~cm} / \mathrm{v})$ during each interstartle interval. For purposes of the statistical analysis, consecutive pairs of light flash and darkness conditions were considered as blocks.

\section{Results}

Pretest. Mean startle amplitude in the P1000 condition of the pretest proved to be $96.7 \%$ of the control level. This minimal difference did not approach statistical significance $(t=.41$, df $=24)$, indicating that for this lead time a single light flash was not sufficient to produce reflex modification. Startle amplitudes were significantly lower in the P60 condition (mean relative amplitude $=84.6 \%, \mathrm{t}=2.52$, $\mathrm{df}=24, \mathrm{p} \leqslant .01$ ), an indication that the light flash was an effective stimulus, at least insofar as it was able to produce reliable reflex inhibition.

Sensitization. The left panel of Figure 1 presents mean relative startle amplitudes during the light-flash and dark phases of the experiment. For each of the four pairs of test trials, startle amplitudes were potentiated by the recent occurrence of visual stimulation. Overall, the sensitized response was $118 \%$ of

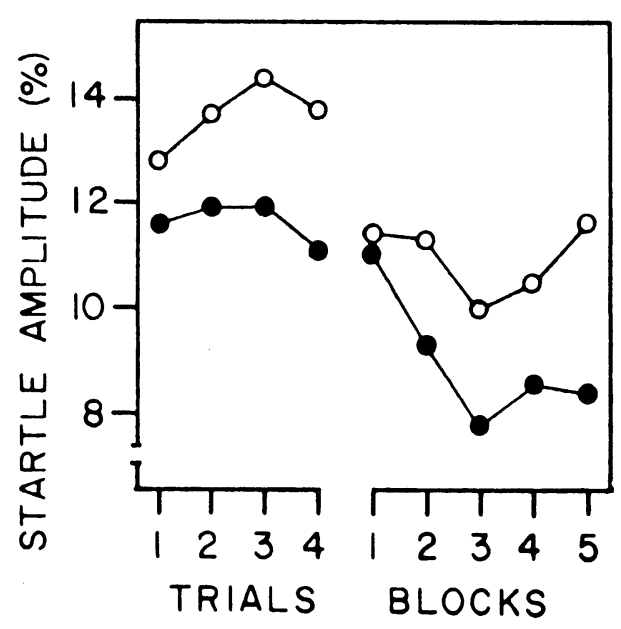

Figure 1. Mean reflex amplitudes to the $10-\mathrm{kHz}$ tone during light flashes (open circles) and darkness (closed circles). 


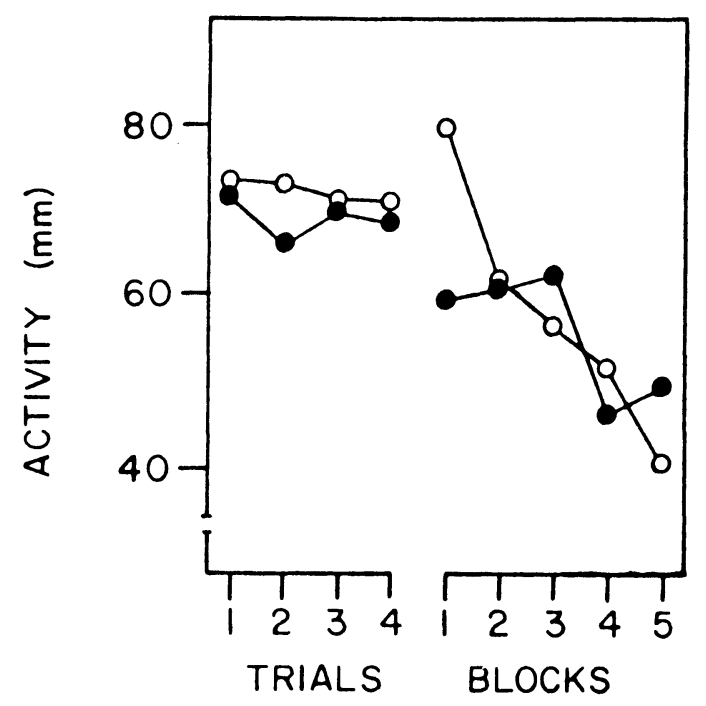

Figure 2. Mean activity scores during light flashes (open circles) and darkness (closed circles).

the control response. Mean raw score amplitudes were $28.2 \mathrm{~mm}$ of beam deflection for the light-flash condition and $23.6 \mathrm{~mm}$ for the dark condition. There was no sign that this advantage declined, either within or between stimulus trains. The analysis of variance, conducted on two levels of visual background, four levels of test trials, and five levels of replication blocks, yielded a highly signficant test statistic for the main effect of light-flash trains $(\mathrm{F}=17.59$, $\mathrm{df}=$ $1 / 23, p \leqslant .001)$. Neither the main effect of test trials $(F=.30$, df $=3 / 69)$, nor the interaction of trials with visual background $(\mathrm{F}=.65, \mathrm{df}=3 / 69)$ approached significance. The effect of treatment replication is depicted in the right panel of Figure 1, where it appears that startle sensitization may have increased across blocks. However, the analysis of variance indicated that neither the main effect of blocks $(F=1.79, \mathrm{df}=4 / 92)$ nor the apparent interaction of blocks with visual background conditions was significant $(F=.60, \mathrm{df}=4 / 92)$, and a review of individual scores revealed a large spread of scores in the first trial series. It is clear from this aspect of our results, first, that sensitization was manifested early with respect to its overall time course, and, second, that sensitized startle reactivity persevered throughout the period of extraneous stimulation. We attribute these characteristics to the fact that the experimental procedure eliminated antagonistic habituation influences.

The left panel of Figure 2 presents mean activity scores during photic stimulation and darkness periods. Here the normal habituation effect of stimulus repetition can be seen. The facilitative consequence of photic stimulation, shown by Schwartzbaum et al. (1972), was seen in the first period of exposure $(t=$ 2.74 , df $=24, p \leqslant .05$ ), but not thereafter. The analysis of variance yielded a significant test statis- tic for the interaction of visual background and replication blocks $(F=2.74, \mathrm{df}=4 / 29, \mathrm{p} \leqslant .03)$. The main effect of replications was significant $(F=$ 6.36 , df $=4 / 92, \mathrm{p} \leqslant .0001$ ), an indication that under the present conditions, motor activity, unlike startle behavior, was highly susceptible to the influence of habituation.

\section{EXPERIMENT 2}

The major purpose of Experiment 2 was to examine the temporal growth of reflex sensitization during the first $32 \mathrm{sec}$ of the stimulus train. An evident problem with the procedures of Experiment 1 is insensitivity to very early and short-lived trends in the sensitization effect. Rapid growth and decay of sensitization would have been undetected, because each reflex sample was taken after $30 \mathrm{sec}$ in the light-flash schedule.

\section{Methods}

Subjects. The subjects were 10 naive male albino rats obtained from the Holtzman Co., Madison, Wisconsin. Prior to the experimental session, they were treated in all respects identically to the animals used in Experiment 1 . At the time of running, their weights ranged from 270 to $340 \mathrm{~g}$.

Apparatus. The apparatus was identical to that of Experiment 1, save that a Grass polygraph (Series 7) was used to amplify the accelerometer signal, which was then fed to a storage CRT, where its amplitude was measured as millimeters of beam deflection. The circuit that provided intertrial activity records in Experiment 1 was disconnected in Experiment 2.

Procedure. After an initial period of acclimatization, each rat received four acoustic startle stimuli spaced $1 \mathrm{~min}$ apart as a calibration and warm-up procedure. One minute after the last calibration trial, the experiment proper began with one of six trial types, a control condition (C) in which the startle tone was presented alone or this same stimulus delivered $1 \mathrm{sec}$ after $2,4,8$, 16 , or 32 light flashes presented at a rate of $1 / \mathrm{sec}$. Unlike the procedures of Experiment 1, startle samples could not be taken at successive points within a single train because of the confounding influence of refractoriness at the shorter intervals. Trial types were presented randomly, again with the limitation that no type was repeated until each had been presented an equal number of times. An exception to this rule was made for $C$ trials, which were sampled twice as frequently as $P$ trials. This procedure is useful when long series of different trial types must be employed, as it reduces the variability associated with control responding. The intertrial interval, i.e., the period of quiet darkness, was variable, with a mean at $1 \mathrm{~min}( \pm 15 \mathrm{sec})$.

\section{Results}

Figure 3 depicts the effects on relative startle vigor of varying the number of prestartle light flashes. Startle reflex amplitudes were potentiated by the photic trains within 4 to $8 \mathrm{sec}$ of the onset of the sensitizing treatment, and sensitization reached its asymptotic peak by $16 \mathrm{sec}$, where reflex amplitude was approximately $150 \%$ of the control value. Mean raw score amplitudes for the control and 16-sec condition were 12.1 and $17.3 \mathrm{~mm}$, respectively. The analysis of variance, conducted on relative startle scores, with the number of prestartle light flashes as 


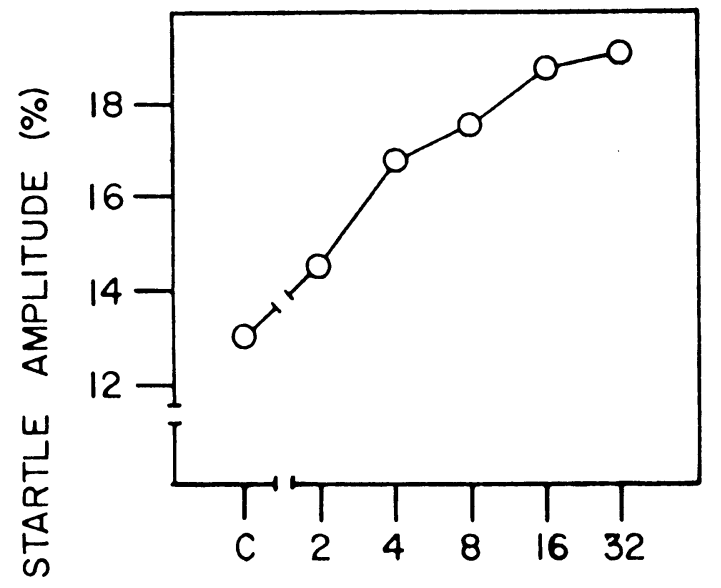

LIGHT FLASHES

Figure 3. Mean reflex amplitudes to the $10-\mathrm{kHz}$ tone presented alone $(C)$ and after different numbers of light flashes.

the relevant within-subjects variable, indicated a significant effect for train length $(F=5.52, \mathrm{df}=5 / 45$, $\mathrm{p} \leqslant .0001$ ), and linearity, with the values of the abscissa arranged on a logarithmic scale, presented the only significant trend in these data $(F=28.39$, df $=1 / 9, p \leqslant .0001)$. This supports the data of Figure 1 and shows that sensitization exhibits a rapid growth within the first $30 \mathrm{sec}$ of stimulation. Additional analysis revealed that the portion of Figure 3 depicting startle reactivity during photic stimulation is closely described $\left(r^{2}=.919\right)$ by the logarithmic relationship: $R=14+\log \mathrm{N}$, where $\mathrm{R}$ is the relative size of the reflex and $N$ is the number of antecedent light flashes.

Our results for this experiment clearly indicate that sensitization did not exhibit early decay, and they extend the results of Experiment 1 by revealing the growth rate of startle sensitization.

\section{DISCUSSION}

There are two perturbations in habituation curves which have been interpreted as reflecting the process of reflex sensitization. In the first, it is observed that repetitive exposure to the eliciting stimulus yields, not a steadily decreasing curve of reflex strength which follows some rational monotonic function, but a complex nonmonotone curve characterized by an early portion of increasing strength (Davis, 1972; Groves \& Thompson, 1970; Hinde, 1970). In the second, it is observed that the presentation of an irrelevant stimulus during the course of exposure to the eliciting stimulus provides a temporary increase in reflex strength. In the first case, it is assumed that exposure to the eliciting stimulus has the dual consequences of habituation and sensitization (Groves \& Thompson, 1970), and that the observed early potentiation of the behavior reveals the advantage enjoyed by sensitization. This is sensitization, "sense
1." Because the curve eventually assumes a decremental course, it is assumed that sensitization is a temporary consequence of stimulus repetition (Groves $\&$ Thompson, 1973). In the second case, the experimental protocol defines the phenomenon of dishabituation and the ensuing performance change has been traditionally attributed to a temporary loss in habitutation (Sokolov, 1960). For a number of reasons, most prominently that reflex enhancement can be obtained in the absence of any prior habituation treatment, dishabituation as a behavioral phenomenon has been attributed to sensitization as a theoretical process (Thompson \& Spencer, 1966). This is sensitization, "sense 2." Because dishabituation wanes with repetitive exposure to the irrelevant stimulus, it may be assumed here also that the process of sensitization declines with its repeated occurrence.

In the two experiments reported here, we studied sensitization as a phenomenon rather than as a hypothetical process. Under the conditions of our experiments, the growth rate of sensitization was rapid; reflex facilitation reached its peak within 16 exposures of the repetitive stimulus (Experiment 1). Thereafter, it was stable in strength, and it did not decline over the course of 120 contiguous exposures or 600 exposures arranged in five blocks (Experiment 1).

The contributions of these data to theoretical conceptions of sensitization, and to our understanding of the role of stimulus repetition, are straightforward, as they agree with other observations that collectively characterize sensitization, "sense 1." For example, Graham (1973) argued, on the strength of evidence derived from an autonomic response, that the assumption that sensitization does not decay is more appropriate than is the original decay hypothesis (Groves \& Thompson, 1970). In order to account for the eventual inflection point in biphasic habituation curves, she assumes only that sensitization reaches its maximum level more quickly than does habituation. Our observation that sensitization does not decay with stimulus repetition supports her contention. But, to turn to sensitization "sense 2," when dishabituation is attributed to sensitization, our observation is anomalous, for it is commonly seen that dishabituation declines with stimulus repetition. This could be found only if sensitization itself habituates. The direction in which a resolution of the anomaly may be found is that of assuming a variety of sources of dishabituation which are differently affected by maintained exposure to the stimuli. Perhaps one source is an evoked orienting reaction; this may yield sensitization only when the stimuli are novel. Other stimuli may alter the learned associative context of the behavior, and thereby yield a generalization decrement in specific S-R pathways. Their effect may diminish, but it may require considerable training before their disruptive influence is lost. And yet other stimuli may enhance reflex activity for as long as they are present with no apparent reduction 
in their force. White noise apparently has this effect on the acoustic startle reaction in the rat.

Regardless of the details of interpretation, our data agree with those of others who show that different sources of reflex enhancement respond differently to the imposition of experimental variables. Some of these may persist in their effects for prolonged time periods. Davis, Svensson, and Aghajanian (1975), for example, reported that $\mathrm{d}$ - and l-amphetamine enhance the reflex sensitizing effects of eliciting stimulus repetition without changing sensitization produced by background white noise. Hoffman, Marsh, and Stein (1969) and Cory and Ison (1979) showed that the latter kind of sensitization persists for durations of background noise exposure of up to $24 \mathrm{~h}$. Together, these various demonstrations suggest caution in assuming that all sources of sensitization or response enhancement reflect the same underlying process.

\section{REFERENCES}

Cory, R. N., \& Ison, J. R. Persistent effect of noise on the acoustic startle reflex in the rat. Animal Learning \& Behavior, 1979, in press.

DAvis, M. Effects of interstimulus interval length and variability on startle response habituation in the rat. Journal of Comparative and Physiological Psychology, 1970, 72, 177-192.

DAvis, M. Differential retention of sensitization and habituation of the startle response in the rat. Journal of Comparative and Physiological Psychology, 1972, 78, 260-267.

Davis, M., Svensson, T. H., \& Aghajanian, G. K. Effects of $\mathrm{d}$ - and l-amphetamine on habituation and sensitization of the acoustic startle response in rats. Psychopharmacologia, 1975, 43, 1-11.

Davis, M., \& WAgner, A. R. Startle responsiveness after habituation to different intensities of tone. Psychonomic Science, 1968, 12, 337-338.

GRAHAM, F. K. Habituation and dishabituation of responses innvervated by the autonomic nervous system. In H. V. S. Peeke \& M. J. Herz (Eds.), Habituation (Vol. 1) Behavioral studies. New York: Academic Press, 1973.
Groves, P. M., LeE, D., \& Thompson, R. F. Effects of stimulus frequency and intensity on habituation and sensitization in acute spinal cat. Physiology \& Behavior, 1969, 4, 383-388.

Groves, P. M., \& Thompson, R. F. Habituation: A dual process theory. Psychological Review, 1970, 77, 419-450.

Groves, P. M., \& Thompson, R. F. A dual-process theory of habituation: Theory and behavior. In H. V. S. Peeke \& M. J. Herz (Ėds.), Habituation (Vol. 1) Behavioral studies. New York: Academic Press, 1973.

HINDE, R. A. Behavioral habituation. In G. Horn \& R. A. Hinde (Eds.), Short-term changes in neural activity and behavior. New York: Cambridge University Press, 1970.

Hoffman, H. S., Marsh, R. R., \& Stein, N. Persistence of background acoustic stimulation in controlling startle. Journal of Comparative and Physiological Psychology, 1969, 68, 280-283.

Ison, J. R., \& HAMmOND, G. R. Modification of the startle reflex in the rat by antecedent changes in the auditory and visual environments. Journal of Comparative and Physiological Psychology, 1971, 75, 157-164.

Ison, J. R., Hammond, G. R., \& Krauter, E. E. Effects of experience on stimulus-produced reflex inhibition in the rat. Journal of Comparative and Physiological Psychology, 1973, 83, 324-336.

ReIter, L. A., \& Ison, J. R. Inhibition of the human eyeblink reflex: An evaluation of the sensitivity of the Wendt-Yerkes method for threshold detection. Journal of Experimental Psychology: Human Perception and Performance, 1977, 3, 325-336.

Russo, J. M., ReIter, L. A., \& Ison, J. R. Repetitive exposure does not attenuate the sensory impact of the habituated stimulus. Journal of Comparative and Physiological Psychology, 1975, 88, 665-669.

Schwartzbaum, J. S., Kreinick, C. J., \& Levine, M. S. Behavioral reactivity and visual evoked potentials to photic stimuli following septal lesions in rats. Journal of Comparative and Physiological Psychology, 1972, 80, 123-142.

Sokolov, E. N. Neuronal models and the orienting reflex. In M. A. B. Brazier (Ed.), The central nervous system and behavior. New York: Josiah Macey, Jr. Foundation, 1960.

Thompson, R. F., \& Spencer, W. A. Habituation: A model phenomenon for the study of neuronal substrates of behavior. Psychological Review, 1966, 73, 16-43.

(Received for publication August 4, 1977; revision accepted December 15, 1978.) 